\title{
GC-MS and FTIR Analysis of Crude Extracts of Carica Papaya Seed
}

\author{
Reuben Agada ${ }^{1}$, Wurochekke Abdullahi Usman ${ }^{2}$, Sarkkiyayi Shehu ${ }^{3}$ \\ ${ }^{1}$ Modibbo Adama University of Technology Yola, Department of Biochemistry, Adamawa State, Nigeria \\ ${ }^{2}$ Modibbo Adama University of Technology Yola, Department of Biochemistry, School of Life Sciences, Adamawa State, Nigeria \\ ${ }^{3}$ University of Technology Yola, Department of Biochemistry, Adamawa State, Nigeria
}

Correspondence Author: Reuben Agada, Modibbo Adama University of Technology Yola, Department of Biochemistry, Adamawa State, Nigeria. E-mail:- Agabaidu73@gmail.com

Received date: 23 August 2019, Accepted date: 20 September 2019, Online date: 22 November 2019

Copyright: $\odot 2019$ Reuben Agada $e t$ al, This is an open-access article distributed under the terms of the Creative Commons Attribution License, which permits unrestricted use, distribution, and reproduction in any medium, provided the original author and source are credited.

\begin{abstract}
Background: Identification, quantitation, and characterization of bioactive principles from Carica papaya seed will further improve discoveries in therapeutic medicine and economic values.

Objective: This study aimed to identify the possible bioactive compounds present in methanol and aqueous extracts of Carica papaya seed using Gas chromatography-mass spectrometry (GC-MS) and Fourier transform infrared spectroscopic (FTIR) analysis. Materials and method: The Carica papaya seed was obtained, air-dried and turned to powdered. Extraction was done with methanol and aqueous using a soxhlet extractor.

Results: The results confirmed the presence of 21 compounds including undecylenic acid (40.33\%), oleic acid (30.21\%), n-hexadecanoic acid (7.55\%), 9-octadecenal (7.09\%) and 9,17-octadecadienal, (Z)- (5.98\%) in methanol extract while oleic acid $(31.58 \%), 9,12$-octadecadienoyl chloride, (Z,Z)- $(13.18 \%)$, undecylenic acid $(12.60 \%)$, nhexadecanoic acid $(7.83 \%), 10$-undecenal $(7.44 \%)$, octadecanoic acid $(5.68 \%)$, 10-undecenoyl chloride $(4.55 \%)$ and hexadecanoic acid, 2,3-dihydroxpropyl ester $(4.08 \%)$ were found in aqueous extract. The FTIR spectroscopic investigation revealed the presence of these functional groups: $\mathrm{C}=\mathrm{C},-\mathrm{C}-\mathrm{O},-\mathrm{O}-\mathrm{H},-\mathrm{N}-\mathrm{O},-\mathrm{C}=\mathrm{O},-\mathrm{C}=\mathrm{C}=\mathrm{C},-\mathrm{S}-\mathrm{H},-\mathrm{O}=\mathrm{C}=0,-\mathrm{C}-$ $\mathrm{H}$, and - $\mathrm{N}-\mathrm{H}$ indicating the presence of alkanes, alkenes, ether compounds, alkyl aryl ether, carboxylic acid, nitro compounds, aliphatic ketones, halides, allenes, thiols, carbonates, amines and alcohols in methanol and aqueous extracts Carica papaya seed.

Conclusion: The present study revealed that extracts of Carica papaya seed contained a lot of metabolites and therapeutic active substances. These substances could be further isolated and investigated to confirm their pharmacological activities. Hence, this study supports the use of the Carica papaya seed in alternative/traditional medicine.
\end{abstract}

Keywords: Carica papaya seed; bioactive compounds; secondary metabolites; GC-MS and FTIR analysis; methanol and aqueous extracts

\section{INTRODUCTION}

Natural products from plants will continue to be extremely important as sources of new drugs with new modes of pharmacological action. These plants produce secondary metabolites that have played an essential role as medicine and lead compounds for new drug development (Castello et al., 2002). Through recent studies on medicinal plants, there have been great developments in the identification and isolation of new therapeutic compounds of medicinal importance from plants for most common and specific diseases (Ertuk et al., 2006, Kumar et al., 2007). Therapeutic agents, oil and gums are all constituents of plants, hence harnessing the constituents of plants will further improve discoveries in therapeutic medicine and economic values. The plants which have pharmacological properties possess bioactive constituents like saponins, alkaloids, flavonoids, tannins, vitamins, and phenolic compounds. In Nigeria, a large population of people depend on alternative/traditional medicine without the knowledge of their chemical constituents (Anaduaka et al., 2013; Ashokkumar and Ramaswamy, 2014). The analysis of these chemical constituents in plants would provide useful insights into their pharmacological properties.

Papaya (from Carib via Spanish), papaw or pawpaw (English) is the fruit of the plant Carica papaya and is one of the 23 accepted species in the genus Carica of the plant family Caricaceae. The Carica papaya is consumed worldwide, either in natural or processed as jam, sweets, and pulp, and to aggregate the nutritional value, other parts of the plant (leaves and seeds) are 
added to some products in the form of teas and flours (Nwofia et al., 20012). The black seeds of the papaya are usually numerous small, black, ovoid, corrugated, peppery seeds about 3/16 in $(5 \mathrm{~mm})$ long, each coated with a transparent, gelatinous aril as presented in Figure 1. They are edible, non-toxic and have a sharp, spicy taste. They are sometimes ground and used as a substitute for black pepper (Aravind, 2013). In Nigeria, different parts of the plant are used traditionally in the treatment of some diseases by different cultural groups (Oboh et al., 20013) and the seed contains phenolic compounds, such as benzyl isothiocyanate, glucosinolates, tocopherols ( $\alpha$ and $\delta$ ), $\beta$-cryptoxanthin, $\beta$-carotene and carotenoids (Kermanshai., 2001, Tang, 1971), while the seed oil contains oleic fatty acid, followed by palmitic, linoleic and stearic acids (Van Breemen and Pajkovic, 2008). The present study aims to identify the bioactive phytochemical components of the methanol and aqueous extracts with the aid of GC-MS and FTIR techniques.

\section{MATERIALS AND METHODS}

\section{Collection of plant material}

The ripe fruits of Carica papaya (red royal) were collected from farmland at Ofuorachi Igalamela-Odolu, Kogi state during dry season. The plant was authenticated by a botanist at the department of Plant Sciences, School of Life Sciences, Moddibo Adama University of Technology Yola, Nigeria. The ripe seeds were removed and rinsed under running tap water and then shade dried at ambient temperature. Thereafter the dried seed sample was pulverized into coarse powder using laboratory blender, ready for extraction.

\section{Preparation of plant extract}

The powdered Carica papaya seed about $(200 \mathrm{~g})$, was extracted with methanol using a soxhlet extractor. The extract obtained was filtered using Whatman filter paper $(15 \mathrm{~cm})$ after which the filtrates were concentrated on a rotary evaporator to obtain the methanol extract. The residue from the methanol extract was soaked in distilled water for 24 hours after which it was filtered using a muslin cloth and Whatman filter paper to obtain the aqueous extract. The methanol and aqueous extracts were subjected to GC/MS and FT-IR analysis.

\section{Gas Chromatography-Mass Spectrometry (GC-MS) Analysis}

Methanol and aqueous extracts of Carica papaya seed were analyzed with the help of a GC-MS analyzer (GC-MS-QP 2010 plus Shimadzu, Japan). The carrier gas helium $(99.999 \%)$ was used at a flow rate of $1 \mathrm{ml}$ per min in split mode (10:1) v/v. Methanol and aqueous extracts $(8 \mu \mathrm{l})$ were injected into the column at $250{ }^{\circ} \mathrm{C}$ injector temperature. The temperature of the oven started at $70{ }^{\circ} \mathrm{C}$ and held for $5 \mathrm{~min}$. It was then raised at a rate of $10{ }^{\circ} \mathrm{C}$ per min to $280{ }^{\circ} \mathrm{C}$ without holding. Holding was allowed for $6 \mathrm{~min}$ at a programmed rate of $5{ }^{\circ} \mathrm{C}$ per min. The temperature of ion sources was maintained at $200{ }^{\circ} \mathrm{C}$. The injector temperature was set at $250{ }^{\circ} \mathrm{C}$ and the detector temperature was set at $250{ }^{\circ} \mathrm{C}$. The mass spectrum of compounds present in samples was obtained by electron ionization at $70 \mathrm{eV}$ and the detector operates in scan mode 50 to $600 \mathrm{Da}$ atomic units. The MS Table was generated through an ACQ mode scan within 0.5 seconds of scan interval at the speed of 666 and fragments from 30 to 350 Da were maintained according to the method reported by Ibrahim et al., (2013). The total running was 21 minutes.

\section{Identification of components}

Interpretation of the mass spectrum of GC-MS was done using the database of National Institute Standard and Technology (NIST) having more than 62,000 patterns. The mass spectrum of the unknown component was compared with the spectrum of the known components stored in the NIST library. The name of the chemical component, molecular weight, and the chemical structure contain in Carica papaya seed extracts were identified.

\section{Fourier Transformed Infrared (FTIR) Spectroscopic Analysis}

Fourier transform infrared spectroscopic (FTIR) analysis of the extracts was carried out using Shimadzu FTIR-8400s Fourier transform infrared spectrophotometer, Japan. Methanol and aqueous extracts of Carica papaya seed were oven-dried to get powders of the different solvent extracts used for FTIR analysis. The dried extracts powder (10 mg) were encapsulated in $100 \mathrm{mg}$ of $\mathrm{KBr}$ pellet, to prepare translucent sample disc and analysis was carried out by scanning the samples through a wave number range of 400 to $4000 \mathrm{~cm}-1$ with a resolution of $2 \mathrm{~cm}-1$. FTIR analyses were performed and the different peaks present and possible chemical interactions were examined.

\section{Statistical analysis}

The results are presented as Mean \pm SEM (Standard Error of Mean). Comparisons between the groups were performed by one-way analysis of variance using Statistical Package for Social Sciences (SPSS) for windows version 28.0 (SPSS Inc., Chicago, IL, USA). Significant differences were compared by Duncan's Multiple Range test; a probability level of less than 5\% (P<0.05) was considered significant.

\section{RESULTS}

The GC-MS chromatogram of methanol and aqueous extracts are shown in Figures 2 and 3. The present study has identified the presence of 8 and 10 bioactive compounds in methanol and aqueous extracts of Carica papaya seed as shown in Table 2 and 3 with their corresponding retention time, molecular formula, molecular weight and structure as well as their relative abundance, which was expressed in terms of peak area (\%). The major compounds contained in methanol and aqueous extracts of Carica 
papaya seed in terms of their relative abundance were undecylenic acid, 9-octadecanoic acid (oleic acid), 9,12-octadecadienoyl chloride, (Z, Z)-, n-hexadecanoic acid (palmitic acid), 10-undecenal, 9-undecenal, 9,17-Octadecadienal, (Z)- and octadecanoic acid (stearic acid) while the minor compounds contained in methanol and aqueous extracts of Carica papaya seed were 13hexyloxacyclotridec-10-en-one, hexadecanoic acid, ethyl ester, 1-octanol, 2-butyl-, Hexadecanoic acid, 1-[[[(2aminoethoxy)hydroxyphinyl]oxy]metyl]-1,2-ethanediyl ester, hexadecanoic acid, 2,3-dihydroxpropyl ester and 10-Undecenoyl chloride.

The FTIR chromatogram of methanol and aqueous extracts are shown in Figures 4 and 5 and the identified functional groups are presented in Tables 4 and 5. The functional groups found in methanol and aqueous extracts of Carica papaya seed are $-\mathrm{C}=\mathrm{C}$, $\mathrm{C}-\mathrm{O},-\mathrm{O}-\mathrm{H},-\mathrm{N}-\mathrm{O},-\mathrm{C}=\mathrm{O},-\mathrm{C}=\mathrm{C}=\mathrm{C},-\mathrm{S}-\mathrm{H},-\mathrm{O}=\mathrm{C}=\mathrm{O},-\mathrm{C}-\mathrm{H}$, and $-\mathrm{N}-\mathrm{H}$ indicating the presence of alkanes, alkenes, ether compounds, alkyl aryl ethers, carboxylic acids, nitro compounds, aliphatic ketones, halides, allenes, thiols, carbonates, amines, and alcohols.

Table 1: Compounds identified in methanol extract of Carica papaya seed

\begin{tabular}{|c|c|c|c|c|c|c|}
\hline $\begin{array}{c}\text { Peak } \\
\text { No }\end{array}$ & $\begin{array}{l}\text { Retention } \\
\text { time }\end{array}$ & Formula & $\begin{array}{c}\text { Molecular } \\
\text { weight }\end{array}$ & Compound Name & Area\% & Structure \\
\hline 1 & 15.974 & $\mathrm{C}_{16} \mathrm{H}_{32} \mathrm{O}_{2}$ & 256 & n-Hexadecanoic acid & 7.55 & \\
\hline 2 & 16.966 & $\mathrm{C}_{18} \mathrm{H}_{32} \mathrm{O}_{2}$ & 280 & $\begin{array}{l}\text { 13-Hexyloxacyclotridec-10- } \\
\text { en-one }\end{array}$ & 1.19 & \\
\hline 3 & 17.718 & $\mathrm{C}_{18} \mathrm{H}_{34} \mathrm{O}_{2}$ & 282 & Oleic acid & 30.21 & \\
\hline 4 & 17.868 & $\mathrm{C}_{18} \mathrm{H}_{36} \mathrm{O}_{2}$ & 284 & Oleic acid & 5.28 & \\
\hline 5 & 18.905 & $\mathrm{C}_{19} \mathrm{H}_{38} \mathrm{O}_{4}$ & 330 & $\begin{array}{l}\text { Hexadecanoic acid, 2,3- } \\
\text { dihydroxpropyl ester }\end{array}$ & 2.37 & \\
\hline 6 & 19.512 & $\mathrm{C}_{11} \mathrm{H}_{20} \mathrm{O}_{2}$ & 184 & Undecylenic acid & 40.33 & \\
\hline 7 & 20.412 & $\mathrm{C}_{18} \mathrm{H}_{34} \mathrm{O}$ & 266 & 9-Octadecenal & 7.09 & \\
\hline 8 & 22.345 & $\mathrm{C}_{18} \mathrm{H}_{32} \mathrm{O}$ & 264 & 9,17-Octadecadienal, (Z)- & 5.98 & \\
\hline
\end{tabular}


Citation: Reuben Agada, et al., 2019. GC-MS and FTIR Analysis of Crude Extracts of Carica Papaya Seed. Australian Journal of Basic and Applied Sciences, 13(11): 51-59. DOI: $10.22587 /$ ajbas.2019.13.11.7

Table 2: Compounds identified in aqueous extract of Carica papaya seed

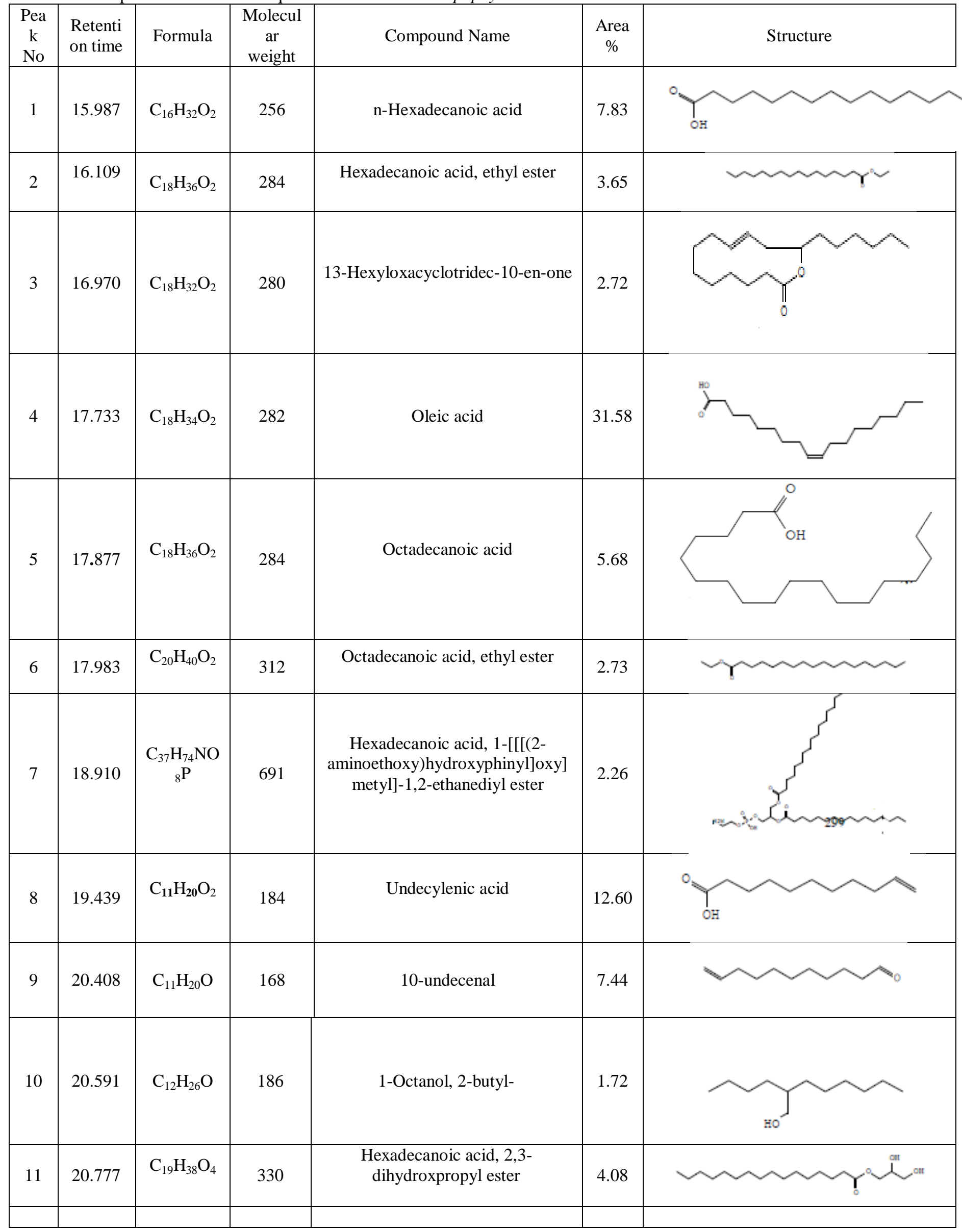


Citation: Reuben Agada, et al., 2019. GC-MS and FTIR Analysis of Crude Extracts of Carica Papaya Seed. Australian Journal of Basic and Applied Sciences, 13(11): 51-59. DOI: $10.22587 /$ ajbas.2019.13.11.7

\begin{tabular}{|c|c|c|c|c|c|c|}
\hline 12 & 22.091 & $\begin{array}{c}\mathrm{C}_{11} \mathrm{H}_{19} \mathrm{Cl} \\
\mathrm{O}\end{array}$ & 202 & 10 -Undecenoyl chloride & 4.55 & \\
\hline 13 & 22.369 & $\begin{array}{c}\mathrm{C}_{18} \mathrm{H}_{31} \mathrm{Cl} \\
\mathrm{O}\end{array}$ & 298 & $\begin{array}{c}9,12 \text {-Octadecadienoyl chloride, } \\
(\mathrm{Z}, \mathrm{Z})-\end{array}$ & 13.18
\end{tabular}

Table 4: FTIR Interpretation of the methanol extract of the Carica papaya seed

\begin{tabular}{|c|c|c|c|c|}
\hline S/NO & Test sample $\left(\mathrm{cm}^{-1}\right)$ & Reference standard $\left(\mathrm{cm}^{-1}\right)$ & Functional group Assignment & Identified Compounds \\
\hline 1 & 709.83 & $665-730$ & $\mathrm{C}=\mathrm{C}$ bend & Alkene \\
\hline 2 & 941.29 & $915-995$ & $\mathrm{C}=\mathrm{C}$ bend & Alkene \\
\hline 3 & 1095.6 & $1150-1085$ & C-O stretch & Ether \\
\hline 4 & 1226.77 & $1200-1275$ & C-O stretch & alkyl aryl ether \\
\hline 5 & 1435.09 & $1395-1440$ & $\mathrm{O}-\mathrm{H}$ bend & carboxylic acid \\
\hline 6 & 1543.1 & $1500-1550$ & N-O stretch & nitro compound \\
\hline 7 & 1712.85 & $1705-1725$ & $\mathrm{C}=\mathrm{O}$ stretch & aliphatic ketone \\
\hline 8 & 1797.72 & $1770-1800$ & $\mathrm{C}=\mathrm{O}$ stretch & Halide \\
\hline 9 & 1944.31 & $1900-2000$ & $\mathrm{C}=\mathrm{C}=\mathrm{C}$ stretch & Allene \\
\hline 10 & 1982.89 & $1900-2000$ & $\mathrm{C}=\mathrm{C}=\mathrm{C}$ stretch & Allene \\
\hline 11 & 2337.8 & $2275-2349$ & $\mathrm{O}=\mathrm{C}=\mathrm{O}$ stretch & carbonate \\
\hline 12 & 2692.72 & $2500-3000$ & O-H stretch & carboxylic acid \\
\hline 13 & 2916.47 & $2840-3000$ & C-H stretch & Alkene \\
\hline 14 & 3086.21 & $3080-3140$ & C-H stretch & Alkene \\
\hline 15 & 3255.95 & $3250-3330$ & N-H stretch & Amine \\
\hline 16 & 3425.69 & $3400-3500$ & N-H stretch & Amine \\
\hline 17 & 3495.13 & $3400-3500$ & N-H stretch & Amine \\
\hline 18 & 3595.43 & $>3500$ & $\mathrm{O}-\mathrm{H}$ stretch & Alcohol \\
\hline 19 & 3796.04 & $>3500$ & $\mathrm{O}-\mathrm{H}$ stretch & Alcohol \\
\hline 20 & 3880.91 & $>3500$ & $\mathrm{O}-\mathrm{H}$ stretch & Alcohol \\
\hline 21 & 3965.78 & $>3500$ & O-H stretch & Alcohol \\
\hline
\end{tabular}

Table 5: FTIR Interpretation of the aqueous extract of the Carica papaya seed

\begin{tabular}{|c|c|c|c|c|}
\hline S/NO & Test sample $\left(\mathrm{cm}^{-1}\right)$ & Reference standard $\left(\mathrm{cm}^{-1}\right)$ & Functional group Assignment & Identified Compounds \\
\hline 1 & 694.4 & $665-730$ & $\mathrm{C}=\mathrm{C}$ bend & Alkene \\
\hline 2 & 1095.6 & $1070-1150$ & C-O stretch & ether compound \\
\hline 3 & 1234.48 & $1200-1275$ & C-O stretch & alkyl aryl ether \\
\hline 4 & 1435.09 & $1395-1440$ & $\mathrm{O}-\mathrm{H}$ bend & carboxylic acid \\
\hline 5 & 1535.39 & $1500-1550$ & $\mathrm{~N}-\mathrm{O}$ stretch & nitro compound \\
\hline 6 & 1643.41 & $1638-1648$ & $\mathrm{C}=\mathrm{C}$ stretch & Alkene \\
\hline 7 & 1712.85 & $1705-1725$ & $\mathrm{C}=\mathrm{O}$ stretch & aliphatic ketone \\
\hline 8 & 2337.8 & $2275-2349$ & $\mathrm{O}=\mathrm{C}=\mathrm{O}$ stretch & Carbonate \\
\hline 9 & 2584.7 & $2550-2600$ & S-H stretch & Thiol \\
\hline 10 & 2685 & $2500-3000$ & O-H stretch & carboxylic acid \\
\hline 11 & 2862.46 & $2850-3000$ & C-H stretch & alkane \\
\hline 12 & 2924.18 & $2850-3000$ & C-H stretch & alkane \\
\hline 13 & 3086.21 & $3000-3100$ & C-H stretch & Alkene \\
\hline 14 & 3132.5 & $3080-3140$ & C-H stretch & Alkene \\
\hline 15 & 3255.95 & $3250-3330$ & N-H stretch & Amine \\
\hline 16 & 3363.97 & $3300-3400$ & N-H stretch & Amine \\
\hline 17 & 3510.56 & $>3500$ & O-H stretch & Alcohol \\
\hline 18 & 3618.58 & $>3500$ & O-H stretch & Alcohol \\
\hline 19 & 3742.03 & $>3500$ & O-H stretch & Alcohol \\
\hline 20 & 3826.9 & $>3500$ & O-H stretch & Alcohol \\
\hline 21 & 3873.19 & $>3500$ & O-H stretch & Alcohol \\
\hline 22 & 3950.35 & $>3500$ & O-H stretch & Alcohol \\
\hline
\end{tabular}


Citation: Reuben Agada, et al., 2019. GC-MS and FTIR Analysis of Crude Extracts of Carica Papaya Seed. Australian Journal of Basic and Applied Sciences, 13(11): 51-59. DOI: $10.22587 /$ ajbas.2019.13.11.7

\section{DISCUSSION}

GC-MS analysis has been employed as a powerful tool for the identification of novel compounds in plant extracts as revealed in Table 1 to 2 . Some of the identified compounds have been reported to exhibit a lot of biological activities. For instance, 9octadecanoic acid (oleic acid) was reported to exhibit anti-inflammatory, antitumor, immunostimulatory, antiandrogenic, antibacterial, antifungal, lipoxygenase inhibitory, hypocholesterolemic and cancer preventive activities Anyasor et al., (2014) and Omotoso et al., (2014). Similarly, Gnanavel and Saral, (2013) also observed the antioxidant activity of this compound. Additionally, hexadecanoic acid (palmitic acid) was the most abundant saturated fatty acid found in the plant. According to Rajeswari et al., (2012), Anyasor et al., (2014) and Omotosho et al., (2014), this compound has been noted to have antioxidant, anti-inflammatory, hypocholesterolemic, antiandrogenic, 5- $\alpha$ reductase inhibitor and hemolytic activities. Gobalakrishnan et al., (2014); Jiang et al., 2013; Mgbeji et al., (2016) also observed its anticancer and antimicrobial activities respectively. The antiinflammatory activity of n-hexadecanoic was revealed from structure and kinetic study carried out by Aparna et al., (2012) due to its ability to inhibit PLA2 competitively.

Other compounds identified in the extracts in terms of relative abundance include undecylenic acid, 9,12-octadecadienoyl chloride, (Z, Z)-, 10-undecenal, 9-undecenal, and 9,17-Octadecadienal, (Z)- which were present in noticeable quantities in Carica papaya seeds, were novel compounds in that their therapeutic attributes and biologic activities have not been previously reported elsewhere. The number of peak values revealed by FTIR spectroscopic analysis of Carica papaya seed extracts demonstrated the presence of functional groups which are indicative of secondary metabolites and other bioactive compounds. The presence of these compounds in Carica papaya seed extract underscores its ability to possess biological activity. This is in line with the work of Maobe and Nyarango, (2013) who reported that these functional groups confirm the presence of secondary metabolites and other phytochemical components present in plants.

\section{CONCLUSION}

The present study revealed that extracts of Carica papaya seed contained a lot of metabolites and therapeutic active substances. These substances could be further isolated and investigated to confirm their pharmacological activities. Hence, this study supports the use of the Carica papaya seed in alternative/traditional medicine. Further research is ongoing to examine the pharmacological activities of the seed extracts especially in the treatment of oxidative stress resulting from hyperglycemia.

\section{ACKNOWLEDGMENT}

We sincerely wish to appreciate and thank Mr. Ibrahim Ahmed Hayatu for his valuable contribution towards the success of this research.

\section{CONFLICTS OF INTEREST}

The authors declare no conflict of interest
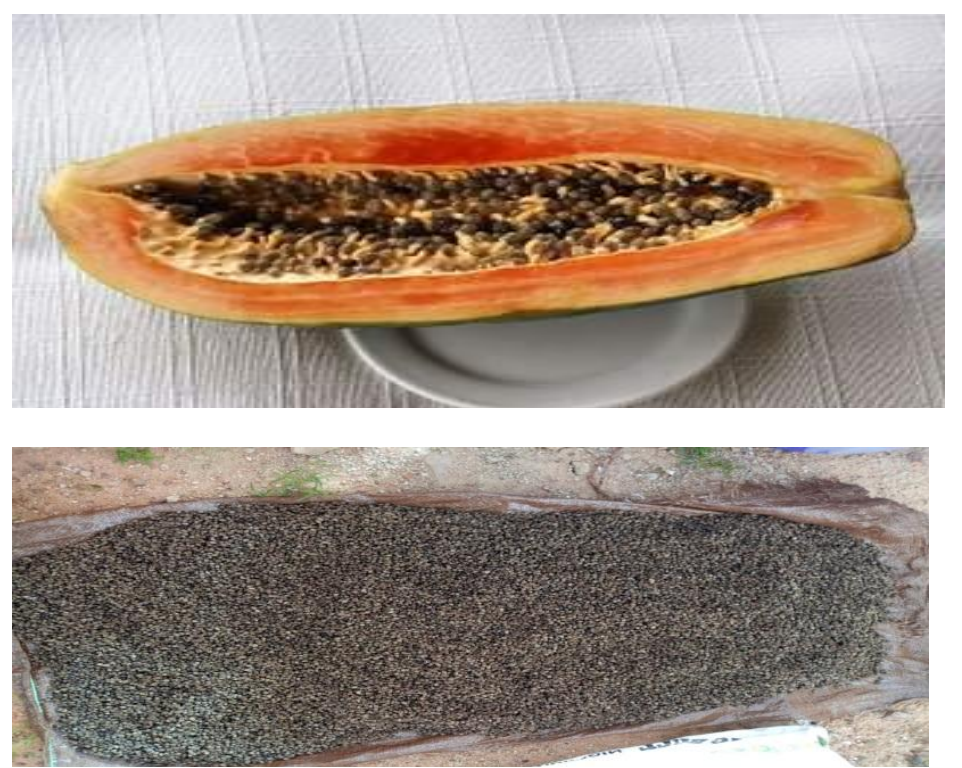

Figure 1: Carica papaya fruit showing the seed and dried seed 


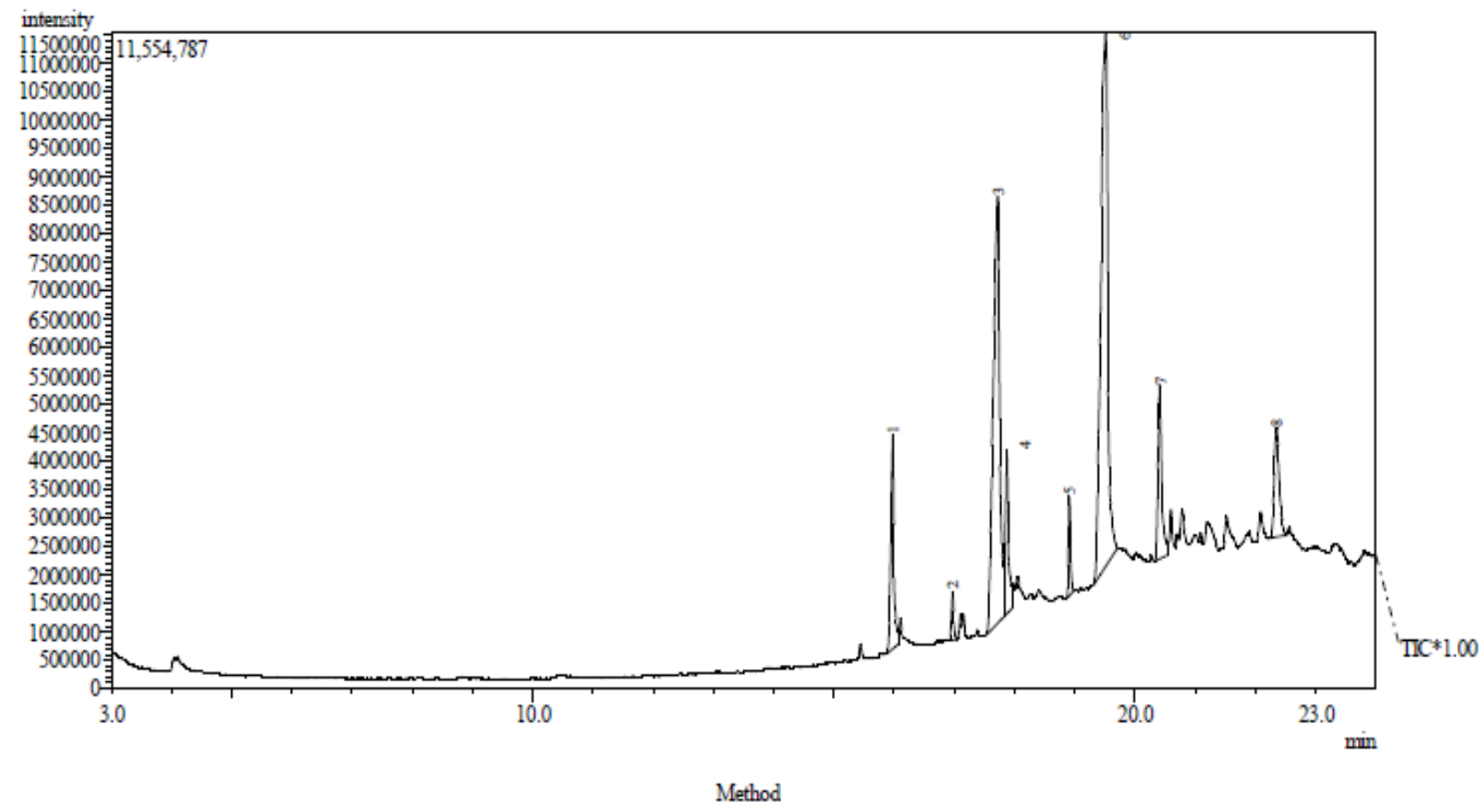

Figure 2: GC-MS Chromatogram of methanol extract of Carica papaya seed

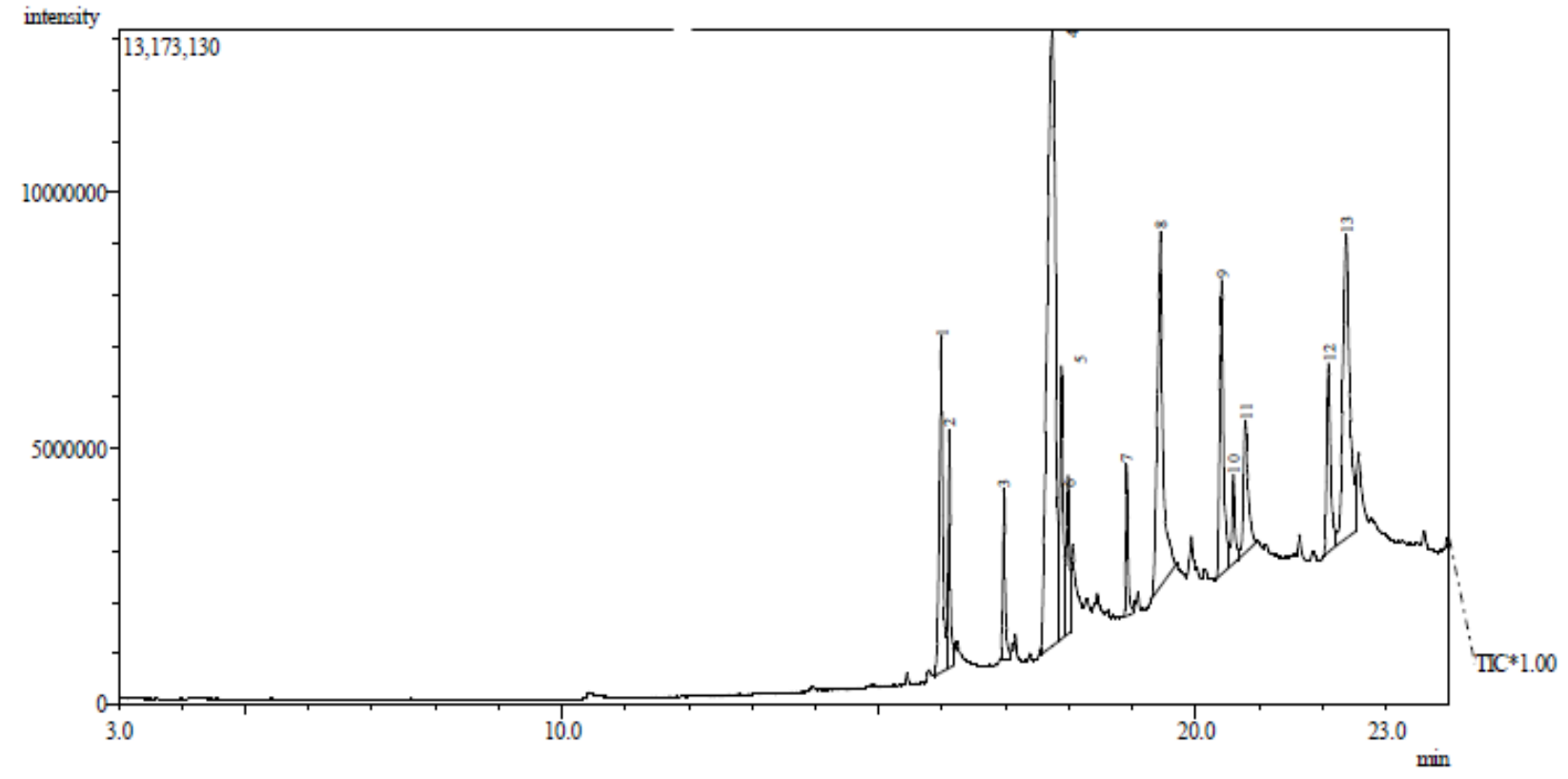

Method

Figure 3: GC-MS Chromatogram of aqueous extract of Carica papaya seed 


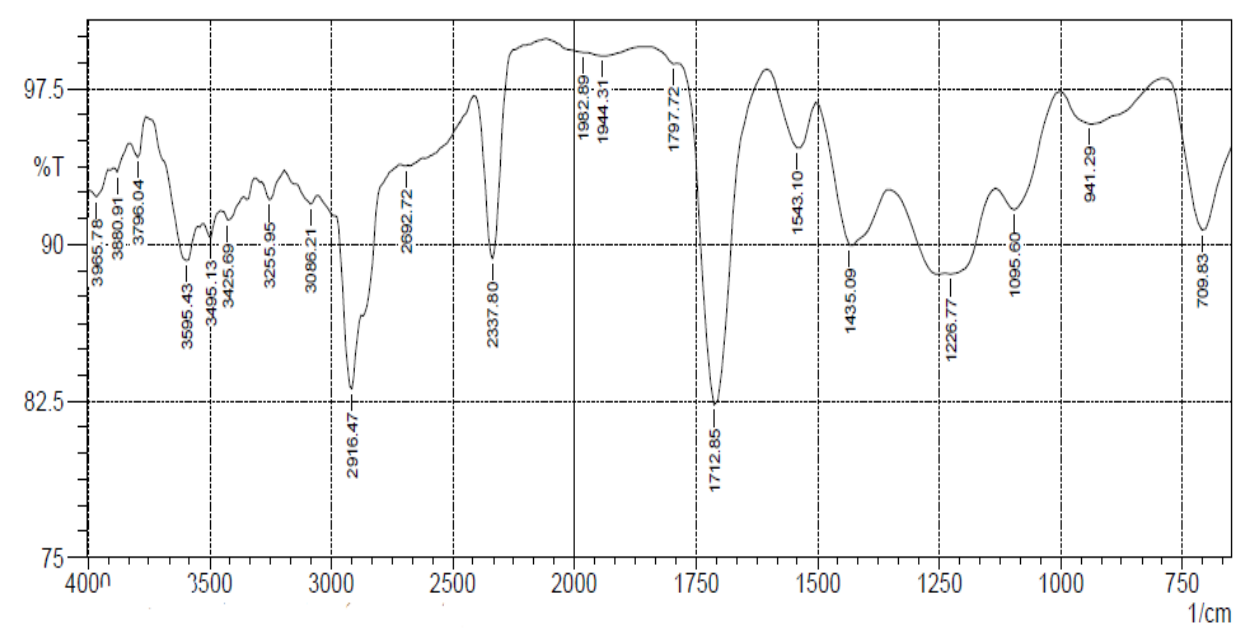

Figure 4: FTIR spectrum of methanol extract of C. papaya se

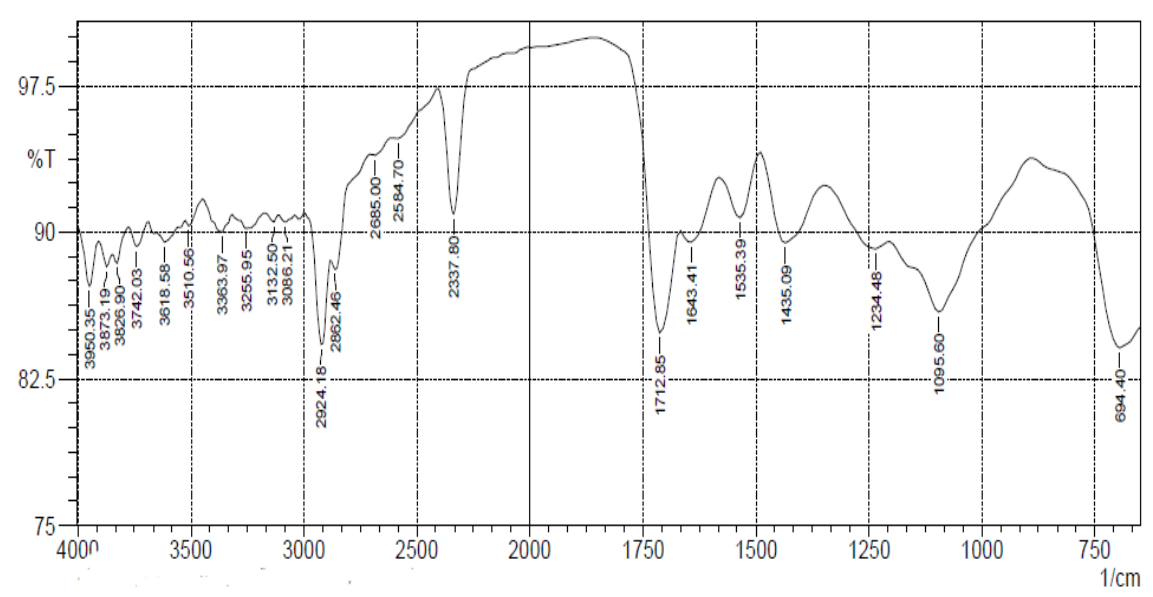

Figure 5: FTIR Spectrum of aqueous extract of C. papaya seed

\section{REFERENCES}

Anaduaka, E. G., Ogugua, V. N., Egba, S. I. and Apeh, V. O., 2013. Investigation of some important phytochemicals, nutritional properties and toxicological potentials of ethanol extracts of Newbouldia laevis leaf and stem. African Journal of Biotechnology, 12(40): 5941-5949.

Anyasor, G. N., Onajobi, F. D., Osilesi, O. and Adebayo, O. O., 2014. Phytochemical constituents in hexane fraction of Costus afer Ker Gawl. Stem. Vedic Research International Phytomedicine, 2 (3): 66-72.

Aparna, V., Dileep, K. V., Mandal, P.K., Karthe, P, Sadasivan, C. and Haridas, M., 2012. Anti-inflammatory property of nhexadecanoic acid. Structural evidence and kinetic assessment. Chemical Biology and Drug Design, 80 (3): $434-349$.

Aravind, G., Debjit, B., Duraivel, S. and Harish, G., 2013.Traditional and Medicinal Uses of Carica papaya. Journal of Medicinal Plants Studies, 1(1): 7-15.

Ashokkumar, R. and Ramaswamy, M., 2014. Phytochemical screening by FTIR spectroscopic analysis of leaf extracts of selected Indian medicinal plants. International Journal of Current Microbiology and Applied Sciences, 3 (1): 395-406.

Castello, M. C., Phattak, A., Chandra, N and Sharon, M., 2002. Indian Journal and Experimental Biology, $40,1378$.

Chinnu, K., Muthukumaran, M., Srinivasan, M and Subasubramanian, V., 2014. GC-MS analysis of some bioactive constituents from isolated ßeta-glucan from Chroococcus turgidus. International Journal of Institutional Pharmacy and Life Science. 4(6):69-74.

Ertuk, O., Kati, H., Yayli, N and Demirbag, Z., 2006. Turkish Journal of Biology, 30, 17.

Gobalakrishnan, R., Manikandan, P. and Bhuvaneswari, R., 2014. Antimicrobial potential and bioactive constituents from aerial parts of the Vitis setosa wall. Journal of Medicinal Plant Research, 8 (11): 454-460.

Gnanavel, V. and Saral, A. M., 2013. GC-MS Analysis of petroleum ether and ethanol leaf extracts from Abrus precatorius Linn. International Journal of Pharma and Bioscience, 4 (3): 37-44.

Ibrahim, M.A., Koorbanally, N.A. and Islam, M.S., 2013. In vitro Anti-Oxidative Activities of The Various Parts of Parkia Biglobosa and GC-MS Analysis of Extracts with High Activity. African Journal of Traditional Complementary and Alternative Medicine, 10(5), 283-291. 
Kermanshai, R., McCarry, B. E., Rosenfeld, J., Summers, P.S., Weretilnyk, E. A and Sorger, G.J., 2001. Benzyl isothiocyanate is the chief or sole anthelmintic in papaya seed extracts. Phytochemistry, 57, 427-435.

Kumar, A. R, Subburathinam, K. M and Prabaker, G., 2007. Asian J. Microbial. Biotechnology. And Environmental. Science. 9, 177 .

Maobe, M. A. G. and Nyarango, R. M., 2013. Fourier transformer infra-red spectrophotometer analysis of Warburgia ugandensis medicinal herb used for the treatment of diabetes, malaria, and pneumonia in the Kisii Region, Southwest Kenya. Global Journal of Pharmacology, 7 (1): 61-68.

Mgbeje, B. I. A., Asenye, E. M., Iwara, I. A. and Ebong, P. E., 2016. Evaluation of phytochemical composition of n-hexane fractions of Heinsia crinita crude leave extracts using gas chromatography-mass spectroscopy (GC-M). World Journal of Pharmacy and Pharmaceutical Sciences, 5 (9): 98-107.

Nwofia, E.; Ojimelukwe, P and Eji, C. (2012). Chemical composition of leaves, fruit pulp, and seeds in some Carica papaya (L) morphotypes. International Journal of Medicinal and Aromatic Plants, 2, 200-206

Oboh, G., Olabiyi, A.A., Akinyemi, A.J, and Ademiluyi, A.O., 2014. Inhibition of key enzymes linked to type 2 diabetes and sodium nitroprusside-induced lipid peroxidation in rat pancreas by water-extractable phytochemicals from unripe pawpaw fruit (Carica papaya). Journal of Basic and Clinical Physiology and Pharmacology, 25, 21-34.

Omotoso, A. E., Olorunfemi, E. O. and Mikailu, S., 2014. Phytochemical analysis of Cnidoscolus aconitifolius (Euphorbiaceae) leaf with spectrometric techniques. Nigerian Journal of Pharmaceutical and Applied Science Research, 3 (1): 38-49.

Rajeswari, G., Murugan, M. and Mohan, V. R., 2012. GC-MS analysis of bioactive components of Hugonia mystax L. (Linaceae). Research Journal of Pharmaceutical, Biological, and Chemical Sciences, 3 (4): 301-308.

Tang, C. S. 2001. Benzyl isothiocyanate of papaya fruit. Phytochemistry, 10, 117-121.

Van Breemen, R. B and Pajkovic, N. 2008. Multitargeted therapy of cancer by lycopene. Cancer Letters, $269,339-351$.

Vuorelaa, P., Leionen, M., Saikku, P., Tammela, P., Rauha, J. P., Wennberg, T et al., 2004. Natural products in the process of finding new drug candidates. Current Medicinal Chemistry, 11(11):1375-1389. 